\title{
Long-Term Observation of a Case of Pulmonary Arteriovenous Fistula with Pulmonary Hypertension
}

\author{
Futoshi Yoshida, Akihiro Terasawa, Masaya Hosoe, \\ Nobuhiko Mishima, Mitsuru SuzuKi and Kazuyuki Goshima
}

\begin{abstract}
A case of pulmonary arteriovenous fistula (PAVF) with pulmonary hypertension (PH) occurring in an adult woman is described. Resection of PAVF was not performed and she has been followed up for 5 years, receiving repeated right cardiac catheterization. We discuss the causal relationship of $\mathrm{PH}$ and the development of PAVF.
\end{abstract}

(Internal Medicine 34: 574-576, 1995)

Key words: cyanosis, cardiac catheterization, anticoagulant therapy

\section{Introduction}

Pulmonary arteriovenous fistula (PAVF) was initially described by Churton in 1897 (1) and more than 400 cases have been reported. But PAVFs associated with pulmonary hypertension $(\mathrm{PH})$ are reported in few cases in the literature. Sapru et al (2) and Sperling et al (3) stressed the importance of detecting $\mathrm{PH}$ in PAVFs preoperatively. Here we report a case of PAVF with $\mathrm{PH}$, receiving serial examinations of cardiac catheterization.

\section{Case Report}

A 45-year-old woman was first seen as an outpatient in March 1989. A plain chest X-ray film obtained by another hospital in 1985 showed normal heart and pulmonary fields according to the medical records (original X-ray film was not available). She remained well until December 1988 when dyspnea and palpitation developed without chest pain. Dyspnea developed gradually and she noticed blueness of her lip and leg edema in February 1989. Since she felt dyspnea on the slightest exertion, she visited our hospital and was immediately hospitalized.

Physical examination revealed severe cyanosis of fingers and toes, but there was no clubbing fingers or telangiectasis. A grade $3 / 6$ continuous murmur was heard along the left upper wall of the chest. A chest X-ray film (Fig. 1a) revealed round opacity $(4.5 \mathrm{~cm}$ in diameter) in the left upper lung field. An electrocardiogram showed right axis deviation and nonspecific ST-T wave changes in the right precordial and inferior leads.
The hemoglobin level was $12.6 \mathrm{~g} / 100 \mathrm{ml}$, and the hematocrit reading was $38.4 \%$. Hepatic function, serum electrolytes and urinalysis were within normal limits. Echocardiography with Doppler technique showed dilatation of the right ventricle and right atrium, and moderate tricuspid regurgitation, but no other abnormal findings. Results of arterial blood gas analysis were $\mathrm{Po}_{2} 45.0 \mathrm{mmHg}$, and $\mathrm{Pco}_{2} 37.5 \mathrm{mmHg}$.

On April 24, 1989, right cardiac catheterization was performed; the results are summarized in Table 1 . The pulmonary arterial pressure was markedly elevated; $62 / 21 \mathrm{mmHg}$ (mean, 35). Angiocardiographic studies (Fig. 1b) showed the PAVF to be fed by the left upper lobe artery with dilatation of the right ventricle and main pulmonary artery. The patient received anticoagulation therapy with warfarin (coumadin) for the treatment of $\mathrm{PH}$ and was followed up as an outpatient.

In June 1993, the second catheterization was performed. The pulmonary arterial pressure was still elevated $(48 / 20 \mathrm{mmHg}$, mean 31), however, the ratio of pulmonary vascular resistance to systemic vascular resistance (PVR/SVR) was not changed (Table 1). The size of the PAVF in the left upper lobe was enlarged to $5.5 \mathrm{~cm}$ in diameter. Clinically, the clubbing of fingers and toes was observed and the hemoglobin level markedly increased to $19.3 \mathrm{~g} / 100 \mathrm{ml}$, suggesting secondary erythrocytosis. The quality of the patient's life was not worsened (NYHA III); she has been followed up as an outpatient for more than five years.

\section{Discussion}

In the present case, the patient was asymptomatic until she

From the Third Department of Internal Medicine, Nagoya University School of Medicine, Nagoya

Received for publication October 11, 1994; Accepted for publication February 14, 1995

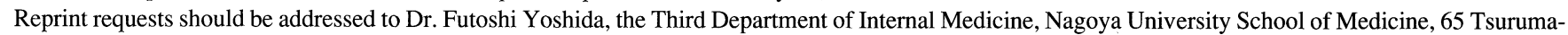
cho, Showa-ku, Nagoya 466 

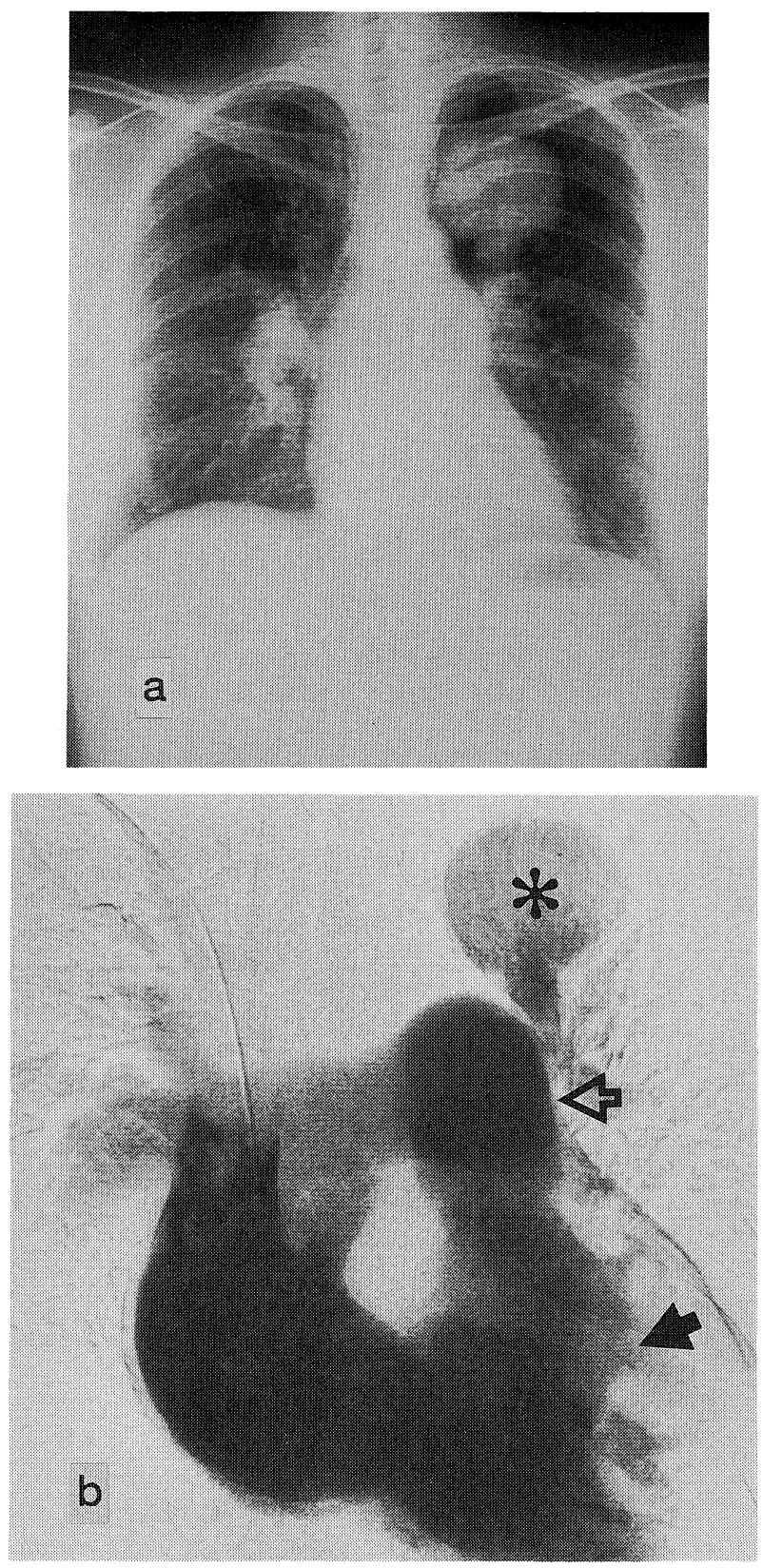

Figure 1. (a) Posteroanterior chest X-ray film obtained on the first admission in 1989. Note the prominent main pulmonary arterial segment and a round opacity in the left upper lung field. (b) Digital subtraction angiocardiogram (injection into the right atrium) shows a large PAVF (*) fed by the left upper lobe artery in the left upper lobe. It also shows dilatation of the right atrium, right ventricle (closed arrow) and main pulmonary artery (open arrow).

noticed dyspnea in 1989 and no abnormal shadow was detected by a chest X-ray film obtained in 1985 . She had no clubbing of fingers nor secondary erythrocytosis at the time of the initial diagnosis. From these data, it is assumed that PAVF with severe hypoxemia developed shortly before the onset of the symptoms in 1989. PAVF such as those associated with the Osler-Weber-
Table 1. Cardiac Catheterization Data

\begin{tabular}{|c|c|c|}
\hline & 1989 & 1993 \\
\hline \multicolumn{3}{|l|}{ Superior vena cava } \\
\hline $\mathrm{O}_{2}$ saturation $(\%)$ & 66 & \\
\hline \multicolumn{3}{|l|}{ Right atrium } \\
\hline mean pressure $(\mathrm{mmHg})$ & 2 & 2 \\
\hline $\mathrm{O}_{2}$ saturation $(\%)$ & 61 & \\
\hline \multicolumn{3}{|l|}{ Right ventricle } \\
\hline pressure $(\mathrm{mmHg})$ & $56 / 2$ & $52 / 4$ \\
\hline $\mathrm{O}_{2}$ saturation $(\%)$ & 62 & \\
\hline \multicolumn{3}{|l|}{ Pulmonary artery } \\
\hline pressure (mmHg) & $62 / 21[35]$ & $48 / 20[31]$ \\
\hline $\mathrm{O}_{2}$ saturation $(\%)$ & 61 & 73 \\
\hline resistance $\left(\mathrm{PVR}\right.$, dyne $\left.\bullet \mathrm{sec} \cdot \mathrm{cm}^{-5}\right)$ & 611 & 368 \\
\hline mean wedge pressure $(\mathrm{mmHg})$ & 6 & 5 \\
\hline \multicolumn{3}{|l|}{ Systemic artery } \\
\hline pressure $(\mathrm{mmHg})$ & $100 / 70[80]$ & $106 / 56[75]$ \\
\hline $\mathrm{O}_{2}$ saturation $(\%)$ & 82.3 & 85.6 \\
\hline resistance $\left(\mathrm{SVR}\right.$, dyne $\left.\bullet \mathrm{sec} \cdot \mathrm{cm}^{-5}\right)$ & 1,640 & 1,024 \\
\hline Cardiac output (1/min) & 3.8 & 5.7 \\
\hline R-L shunt (\%) & 46 & 49.6 \\
\hline Resistance ratio (PVR/SVR) & 0.37 & 0.36 \\
\hline
\end{tabular}

Rendue syndrome can be regarded as congenital. In contrast, acquired PAVFs have been reported in association with hepatic cirrhosis and certain other pulmonary disorders including pulmonary traumatic injury $(4,5)$. In the present case, there was no history which indicated disorders such as those mentioned above and the etiology of PAVF was unknown. But it could be postulated that the development of the vascular malformations in the presence of $\mathrm{PH}$ may be the result of rupture of congenital hypoplastic vascular septa or an increase in the size of shunt through an enlargement of anatomically normal arteriovenous shunts known to exist in most organs at the precapillary level.

$\mathrm{PH}$ was also detected by the initial examination. The etiology of $\mathrm{PH}$ in this case remains unexplained; the usual causes of $\mathrm{PH}$, such as mitral stenosis, chronic thromboembolic disease or pulmonary venoocclusive diseases, were not present in this case, and primary PH cannot be excluded. On the other hand, severe hypoxemia due to PAVF could lead to vasoconstriction of pulmonary small arteries. However, it may be possible to hypothesize that microscopic PAVF, which provided low resistance pathways through the lung, could enlarge and become clinically significant with the development of PH. In favor of our view, Ellison et al showed physiologic enhancement of shunts via PAVFs when the pulmonary arterial pressure exceeded $40 \mathrm{mmHg}(6)$. In the present case, PVR/SVR showed no significant change after four years with enlargement of PAVF, which suggested that PAVF might hemodynamically compensate for the advance of the pulmonary artery vasculopathy. And it might play a role in preventing the patient's condition from worsening over the past 5 years.

Treatment of PAVF with PH has not been established. Removal of PAVF in such a hemodynamic state may raise the 


\section{YosHidA et al}

pulmonary arterial pressure further, and, therefore, resection of such arteriovenous communications would be contraindicated (3). Rodan et al reported a case which illustrated this predicted complication, that is, worsening of $\mathrm{PH}$ after resection of PAVF (7). In the present case, the patient is treated with anticoagulant drug for $\mathrm{PH}$ and nonspecific therapy for persistent dry cough. Anticoagulant therapy is recommended for patients with not only thromboembolic $\mathrm{PH}$ but also primary $\mathrm{PH}(8,9)$.

In the present case, $\mathrm{PH}$ was detected by the initial examination and cardiac catheterization was repeated after four years and the patient has been followed up as an outpatient for more than five years. To the best of our knowledge, there is no case report of PAVF with PH estimated by serial cardiac catheterization. A careful observation of this patient will contribute to the better understanding of the pathophysiology of this disease.

Acknowledgements: We wish to thank Dr. Seiichi Matsuo, Dr. Tatsuaki Matsubara and Dr. Ken-ichi Ito for their helpful discussions.

\section{References}

1) Churton T. Multiple aneurysms of the pulmonary artery. Br Med J 1: 1223, 1897.

2) Sapru RP, Hutchison DCS, Hall JI. Pulmonary hypertension in patients with pulmonary arteriovenous fistulae. Br Heart J 31: 559, 1969.

3) Sperling DC, Cheitlin M, Sullivan RW, Smith A. Pulmonary arteriovenous fistulas with pulmonary hypertension. Chest 71: 753, 1977.

4) Dines DE, Arms RA, Bernatz PE, Gomes MR. Pulmonary arteriovenous fistulas. Mayo Clin Proc 49: 460, 1974.

5) Sheikhzadeh A, Paydar MH, Ghabussi P, Hashemian M, Hakim HS. Pulmonary arteriovenous fistulas. Case presentations and clinical recognition. Herz 8: 179, 1983.

6) Ellison LT, Hall DP, Yeh T, et al. Physiological alterations in increased pulmonary blood flow with and without pulmonary hypertension. J Appl Physiol 16: 305, 1961.

7) Rodan BA, Godwin JD, Chen JT, Ravin CE. Worsening pulmonary hypertension after resection of arteriovenous fistula. Am J Radiol 137: 864, 1981.

8) Fuster V, Steele PM, Edwards WD, McGoon MD, Frye RL. Primary pulmonary hypertension: natural history and the importance of thrombosis. Circulation 70: 580, 1984.

9) Rich S. The medical treatment of primary pulmonary hypertension. Proven and promising strategies. Chest 105: 17S, 1994. 